\title{
MONOTONICITY AND CONVEXITY OF S-MEANS
}

\author{
ALFRED WitKowsKi
}

Abstract. For real $\alpha, r, s$ and positive $x, y$ we define S-means by

$$
S(\alpha ; r, s ; x, y)=\frac{E\left(r, s ; x^{\alpha+1}, y^{\alpha+1}\right)}{E\left(r, s ; x^{\alpha}, y^{\alpha}\right)},
$$

where $E$ is the Stolarsky mean. $S$ contains Gini, Heronian and many other known means. In this paper we investigate convexity properties of $S(\alpha)$ and obtain new inequalities between Gini, Heronian and Stolarsky means.

The results lead to new inequalities for generalized Heronian means and reveal new properties of Stolarsky means.

Mathematics subject classification (2010): 26D15.

Keywords and phrases: S-means, logarithmic convexity.

\section{REFERENCES}

[1] AlZer H., Über eine einparametrige Familie von Mittelwerten, Bayer. Akad. Wiss. Math.-Natur. Kl. Sitzungsber. , 1987 (1988), 1-9.

[2] CZInder P. And PÁles Zs., Some comparison inequalities for Gini and Stolarsky means, Math. Inequal. Appl., 94 (2006), 607-616.

[3] Leach E. AND Scholander M., Extended mean values II, J. Math. Anal. Appl., 92 (1983), 207223.

[4] Neuman E., PÁles Zs., On comparison of Stolarsky and Gini means, J. Math. Anal. Appl., 278 (2003), 274-285.

[5] PÁles Zs., Inequalities for sums of powers, J. Math. Anal. Appl., 131 (1988), 265-270.

[6] PÁles Zs., Comparison of two variables homogeneous means, International Series of Numerical Mathematics, vol. 103, Birkhäuser Verlag, Basel, 1992, 59-70

[7] Qi F, AND CHEN CH.-P., Monotonicity of ratio between the generalized logarithmic mean, Math. Inequal. Appl., 103 (2007), 559-564.

[8] Witkows Ki A., Weighted extended mean values, Colloq. Math., 1001 (2004), 111-117. [ONLINE: RGMIA Research Report Collection, 7(1), Article 6, 2004 http:/rgmia.vu.edu .au/v7n1.html]

[9] Witkowski A., Convexity of weighted Stolarsky means, J. Ineq. Pure and Appl. Math., 72 (2006), Article 73. [ONLINE: http://jipam.vu.edu.au/article.php?sid=670]

[10] WitkowsKi A., Comparison theorem for two-parameter means, Math. Inequal. Appl., 12, 1 (2009), $11-20$. 